\title{
A STUDY OF THE RELATIONSHIP BETWEEN THE NUMBER OF TREES PER ACRE AND DISPERSION
}

\author{
By C. B. GILL \\ Manitoba Forest Service, Winnipeg, Manitoba \\ INTRODUCTION
}

Trees growing in a natural stand are more or less unevenly distributed, and in any case, are not systematically distributed. In sizing up a stand of timber, an advance growth understorey or an area reproduced after clearing, we therefore like to measure in addition to the number of trees per acre, a second factor, i.e., dispersion of the trees on the area. The first factor-number per acre, offers no difficulties, as sampling by means of plots or strips will give us any accuracy desired.

The factor of dispersion per acre is not so easily handled. The method of percentage frequency has been widely used in recent years. In this method it is usual to select square plots or quadrats of regular size, each quadrat being a definite fraction of an acre. For example, in the Regeneration Survey initiated by the Dominion Forest Service, regeneration after logging or fire has been tabulated on systematically arranged quadrats, each of which is $6.6 \mathrm{x}$ 6.6 feet square. Each one of these quadrats is $1 / 1000$ of an acre, and 1,000 quadrats make an acre. If one or more young trees are found on a quadrat it is registered as a success. Thus, if 900 quadrats are filled, the success for the whole acre (or stand) is 90 per cent, while if only 100 quadrats are filled the success is tabulated as 10 per cent. The stand per acre of regeneration is recorded by making a complete count of young trees on every 20th quadrat. By this method, therefore, the two factors, number per acre and frequency per cent, are both measured.

The milacre quadrat system of noting per cent frequency, coupled with the recording of number per acre on a lesser number of quadrats, has merit on account of its simplicity of operation, and is probably as good a system as could be devised. However, there are difficulties in drawing conclusions on the success or failure of regeneration in any region, due to the complex relationship of the variables involved. For example, the correlation of the results of two sets of observations, one made in a plantation and the other in a natural forest is not simple. Again, older sets of observations made with different quadrat size are not easily compared with observations based on the milacre quadrat.

Anyone using frequency per cent is faced with two problems:

1. The relationship between the manner of distribution of the trees in the stand and per cent success.

2. The relationship between quadrat size and per cent success.

In the following, these relationships will be examined in a mathematical way, and by the help of graphs it is hoped that a practical solution of the problems mentioned above may be indicated. 


\section{MANNer of Distribution}

Trees may be distributed over an area in three ways which may be expressed by the terms,-systematic, random and heterogeneous.

(1) The systematic distribution is illustrated by the newly established plantation, where the young trees are evenly spaced. In this case, assuming that there are 1,000 trees to the acre, and 1,000 quadrats to the acre, there will be one tree on each quadrat. Each of the quadrats will be tallied as successful, and the success of the whole area will be registered as 100 per cent,--see Fig. 1. We know that for all practical

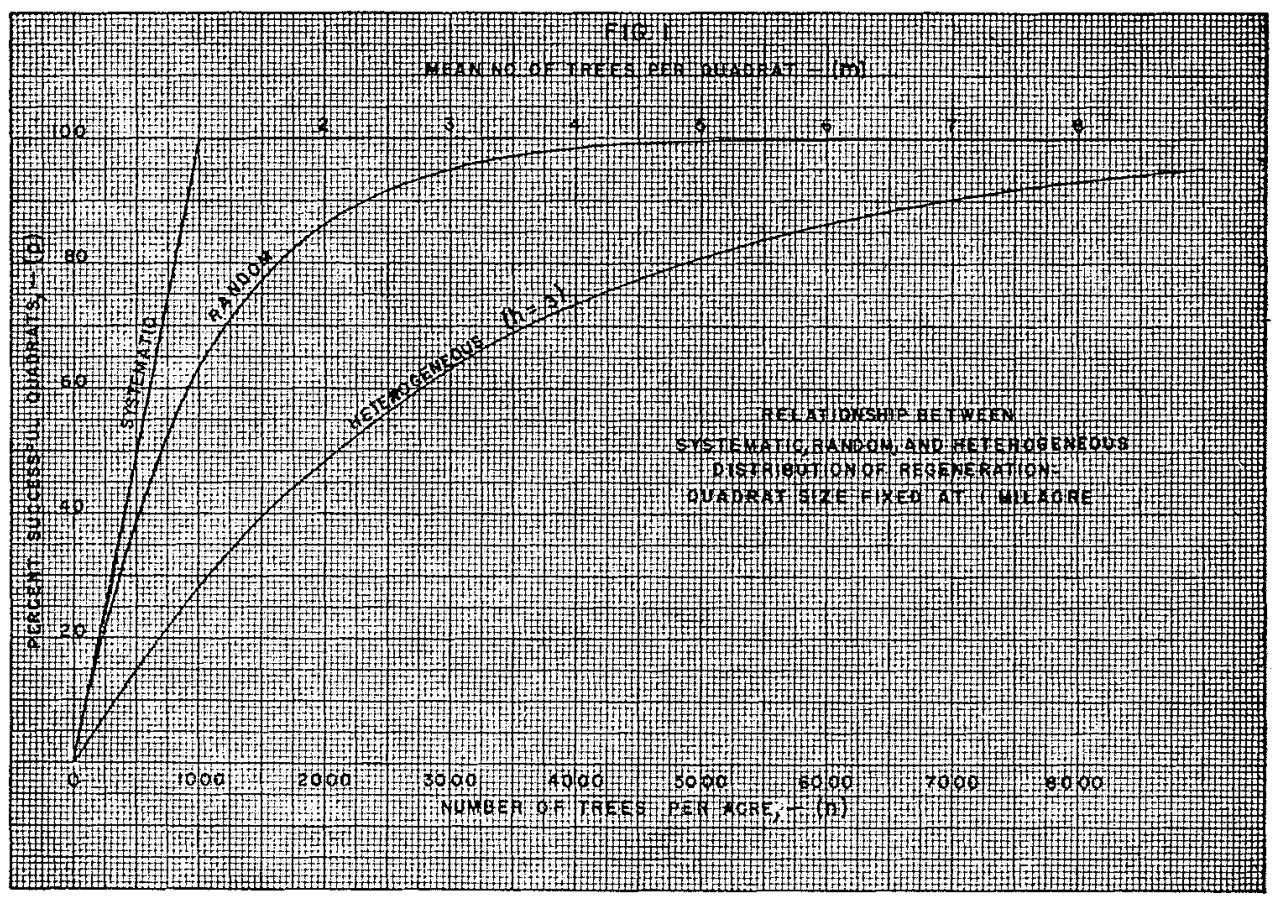

purposes such a favourable reproduction cannot be found in any natural forest, and indeed is not likely to be found even in a plantation a few weeks after it has been established.

(2) The random or chance distribution of trees may perhaps be found in very well stocked natural forests. The assumption has to be made that there is a homogeneity of seed supply and a homogeneity of survival over the whole area. That is to say, each quadrat has an equal chance of producing a tree. Then, if there are 1,000 trees per acre, and also 1,000 quadrats per acre, it can be shown by the calculus of probability that the success of stocking will be, on the average, 63.2 per cent. With the same size quadrat, 2,000 trees per acre will allow 86 per cent of the quadrats to be stocked; 3,000 trees will give 95 per cent; and 5,000 trees will be required to produce 99 per cent successful stockingsee Fig. 1. 
(3) In the third case, we allow the factor of heterogeneity, which exists in practice in all natural stands to obtrude. It is not hard to think of conditions which cause this heterogeneity of survival in different parts of the type. For example, the location of the seed trees, variations in seedbed due to other vegetation, the presence of rotting stumps, or logs-all these factors will make for heterogeneity in distribution of seedlings. An examination of the data obtained by the Dominion Forest Service in 1946, 1947 and 1948, in a study of regeneration after logging and fire, in the Mixedwood Section (B.18) of the Boreal Forest in Western Manitoba and Northern Saskatchewan, indicates that there may be a mathematical relationship between the random distribution illustrated above, and the heterogeneous distribution which was found to occur here. In this case, using milacre quadrats and 1,000 trees to the acre, the per cent success was about 22 per cent.

The three forms of distribution discussed above are illustrated in Fig. 1, by the straight line of systematic distribution, and the curves of random and actual or heterogeneous distribution. In this graph, the per cent quadrat success is plotted over the number of trees per acre, while the number of quadrats per acre is set at 1,000 .

\section{QuAdRat Size}

Foresters in the United States and Canada, at one time or another, have used quadrats of various sizes, ranging all the way from $1 / 4$ milacre to 8 milacres, or in other words, from 4,000 down to 125 quadrats per acre. No doubt the idea in each case was to make the quadrat size approximately equal to the area occupied by the average tree in a properly stocked stand at a certain age. Ecologists have used quadrat sizes as small as 6 inches by 6 inches, or 174,240 to the acre, this small size being considered necessary in view of the high normal stocking of herbs and grasses.

In the discussion below, it is convenient to use as alternatives, the number of quadrats per acre, (c), and the quadrat size in milacres, (s). These are related by the formula: $-s=\frac{1000}{c}$ and $c=\frac{1000}{\mathrm{~s}}$ We must also define (m) as the mean number of trees per quadrat so that $m=\frac{n,}{c}(n)$ being the number of trees per acre.

If the distribution is systematic, as in a plantation, then per cent success will be 100 , as long as (m) is greater than or equal to unity. If, however, $(m)$ is less than one, then $(p)$ decreases in direct proportion to $(m)$. This is illustrated in Fig. 1, where it will be noted the $(\mathrm{m})$ values are given along the top of the form. For example, 1000 trees systematically distributed over an acre will give a per cent success of 100 .

If the distribution is random, quadrat size affects per cent success in a very marked manner, even though the number of trees per acre is fixed. This is illustrated by Fig. 2, where per cent success ( $P$ ) is plotted over number of trees per acre (n). A curve has been drawn for five values of (c), number of quadrats per acre,-100,500,1000,2000, and 5000. In order to get the necessary scope, it has been necessary to use a logarithmic scale on the horizon- 
tal axis. As an example, let there be 1,000 trees per acre. An inspection of the curves for the five values. of (c) will show that per cent success will be 100 per cent where (c) is 100 , that is, where the quadrat size is 10 milacres. With 2 milacre quadrats, 1,000 trees will show 86 per cent, while the same number of trees will register 63,39 and 18 per cent with $1,1 / 2$ and $1 / 5$ milacre quadrats.

If the distribution of trees is poorer than random, that is; heterogeneous, then the effect of quadrat size on sucecss will depend on the relationship between the random and the heterogeneous distribution.

\section{Mathematics of Random Distribution}

The relationship of the three variables which have to be considered in a purely random or chance distribution of successful seedlings, as measured by the quadrat system, has now to be dealt with. This is merely a mathematical problem and depends on the theory of probability.

The three variables in the problem of a chance or random distribution of successful seeding are as follows:

(1) The percentage of successfully stocked quadrats (P).

(2) The total number of quadrats per acre (c).

(3) The number of seedlings, etc., per acre ( $n$ ).

The writer has constructed a formula showing the relationship between these variables where the seedlings have a random distribution, and success is registered as a percentage of stocked quadrats. If per cent success ( $P$ ) is made the dependant variable, the formula is as follows:

$$
\mathrm{p}=100\left\{1-\left(\frac{c-1}{c}\right)^{\mathrm{n}}\right\}
$$

Formula 1

The formula may be shortened by treating ( $\mathrm{p}$ ) as a proportion of unity, rather than as a percentage, so that-

$$
\mathrm{P}=1-\left(\frac{\mathrm{c}-1}{\mathrm{c}}\right)^{\mathrm{n}}
$$
then,-

If we let $\mathrm{q}=$ the proportion of unsuccessful quadrants, since $\mathrm{p}+\mathrm{q}=1$,

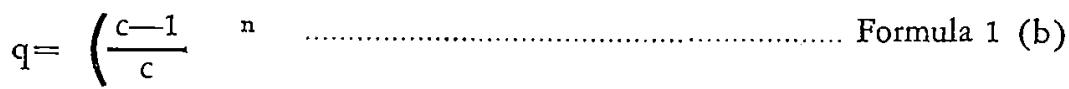

It has been pointed out to the writer that the ordinary textbook formula, corresponding to Formula 1 (a) is,-

$\mathrm{p}=1-\mathrm{e}^{-\mathrm{m}}$

In this formula (e) is the base of the Naperian logarithms, and $e^{-m}$ can be read from a table of exponential functions which gives results for different values of $(\mathrm{m})$. For all practical purposes, the (e) formula gives the same results as Formula 1, except that the former produces increasingly inaccurate results as the value of (c) falls below 100, while Formula 1 is correct for all values. 
Although we are at present mainly concerned with the curve for 1,000 quadrats per acre, nevertheless the curves for lower and higher numbers of quadrats per acre are of interest as showing the relationship between the three variables. For example, let us set the success at 50 per cent. Glancing at the sheaf of curves in Figure 2, it will be seen that the $c=100$ curve is intercepted at about 70 trees per acre, the $c=500$ curve at 350 , the $c=1,000$ at 700 , the $c=2,000$ curve at 1,400 , and the $c=5,000$ curve at 3,500 trees per acre. This means in effect that the mean number of trees per quadrat is

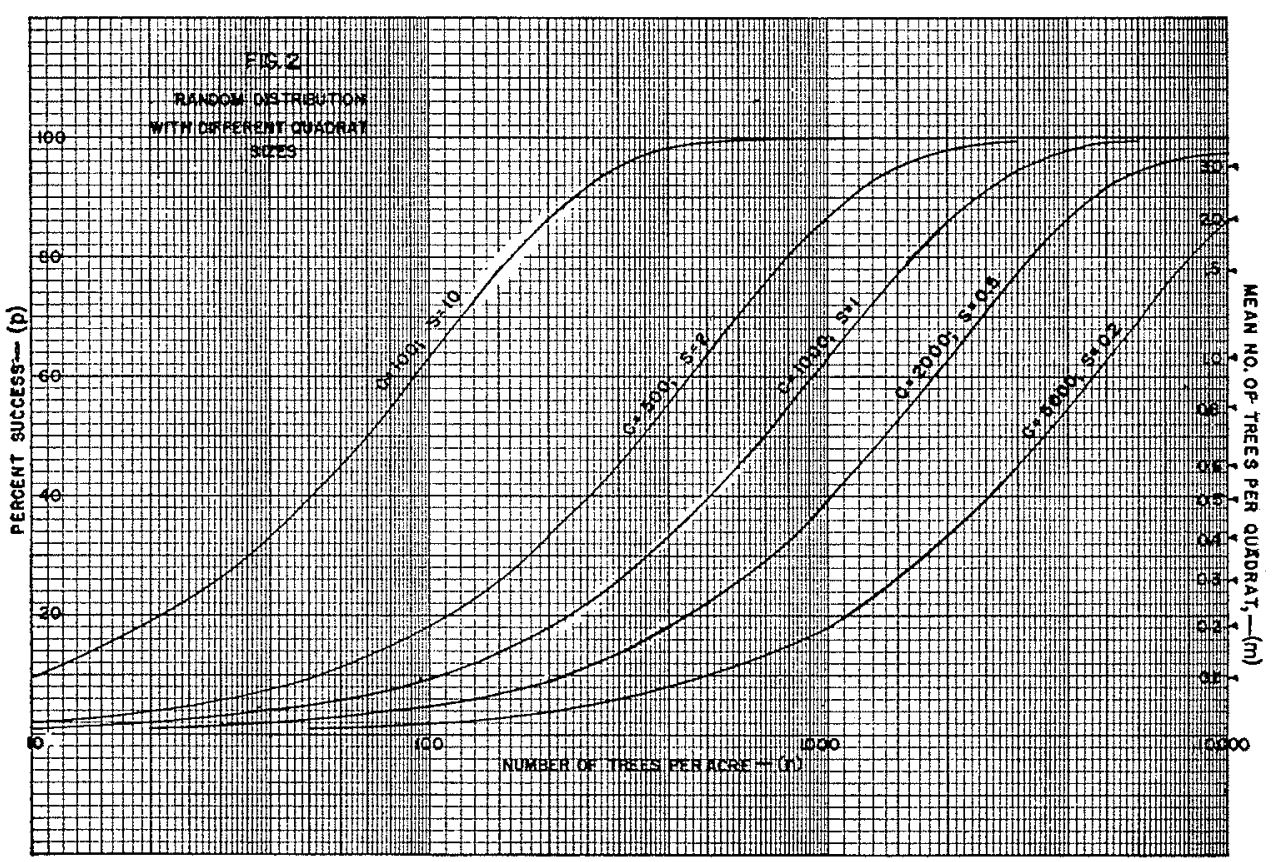

approximately 0.7, (a closer calculation gives 0.69). If this were expressed as a formula, it would read:-if $(p)$ is 50 , then $\frac{n}{c}=m=0.69$. For each value of $(m)$, it can be shown that there is a fixed value for $(p)$. In Fig. 2, the $(m)$ values have been indicated on the right of the graph, with the corresponding ( $p$ ) values on the left. This gives us an easy method of constructing curves for new values of (c). For example, we wish to construct the curve of random distribution where $c=4,000$. We take the various $(\mathrm{m})$ values shown on the right of Fig. 2 , in turn. When $m=0.1$, then $P=9.5$, and since we have fixed (c) at 4,000 , then from the formula, $m=\frac{\mathrm{n}}{\mathrm{c}}$ we determine that $(n)$ will be 400 . We then plot a point opposite the $(m)$ value 0.1 and above the $(n)$ value of 400 . Other points may be plotted by determining the 
(n) value corresponding to the $(\mathrm{m})$ values, $0.2,0.3,0.4$, etc., and the whole curve, $c=4,000$ is readily determined.

In order to be able to conveniently determine how many trees per acre are needed to produce a certain percentage of stocking, Formula 1 may be altered so as to make $(n)$ the dependant variable. This new formula is:-

$$
\mathrm{n}=\frac{\log \left(1-\frac{\mathrm{p}}{100}\right)}{\log \left(\frac{\mathrm{c}-1}{\mathrm{c}}\right)}
$$

The relationship between number of trees per acre and percentage of successful quadrats as derived from Formula 3, may be expressed in tabular form as shown below:

\begin{tabular}{|c|c|c|c|c|c|c|}
\hline \multirow{3}{*}{$\begin{array}{c}\text { Per Cent } \\
\text { Successful } \\
\text { Quadrats (p) }\end{array}$} & \multicolumn{5}{|c|}{ Total Number of Quadrats per Acre (c) } & \multirow{3}{*}{$\frac{\mathrm{n}}{\mathrm{c}}=\mathrm{m}$} \\
\hline & 100 & 500 & 1000 & 2000 & 5000 & \\
\hline & \multicolumn{5}{|c|}{ Number of Trees per Acre (n) } & \\
\hline 99 & 458 & 2300 & 4603 & 9208 & 23015 & 4.60 \\
\hline 90 & 229 & 1150 & 2301 & 4604 & 11507 & 2.30 \\
\hline 70 & 120 & 601 & 1203 & 2407 & 6017 & 1.20 \\
\hline 50 & 69 & 346 & 693 & 1386 & 3464 & 0.69 \\
\hline 30 & 35 & 178 & 357 & 713 & 1783 & 0.36 \\
\hline 10 & 10 & 53 & 105 & 211 & 527 & 0.105 \\
\hline
\end{tabular}

Heterogeneous Distribution

The question of whether there is a mathematical relationship between random distribution and the actual distribution of natural stands must now be dealt with.

As explained above, in order to have a truly random distribution we must have a homogeneous universe. It seems unlikely that a natural stand will fulfill this condition completely. However, a stand which, in its early stages, is somewhat overstocked, may be brought to approximately random distribution by judicious thinning.

The ordinary, untreated, natural forest will not be a homogeneous universe, but will be a mosaic of different conditions affecting regeneration and survival in different ways. The trees will be less regularly distributed than they would be in a homogeneous universe. They will tend to be grouped, and consequently with a given number of trees per acre there will be a greater number of blank quadrats and a lower per cent of quadrat success than would occur with the same number of trees in a random distribution.

In order to express the varying degrees of departure from the random distribution, a new variable, referred to as a "heterogeneity index", and represented by (h) is now introduced, see Fig. 3 . In this graph, the random distribution with milacre quadrats, as defined by the curve $c=1,000$ and $h=1$, is given the (h) value of 1 . Curves for $(h)$ values of 3 and 5 are 
also plotted. The $(m)$ values are recorded across the top of the form, and since (c) is now a fixed value, they vary directly as (n).

The curve for the (h) value of 3 may be plotted as follows:-

For each ( $p$ ) value in the random distribution, (where $h=1$ ), find the corresponding $(\mathrm{m})$. Multiply this $(\mathrm{m})$ value by 3 and plot this opposite the original $(p)$ value. For example, the $(m)$ value for $p=63$, in the random distribution is 1. Multiply this by 3 , getting a new (m) value of 3 . Plot a point with a $(\mathrm{p})$ value of 63 and an $(\mathrm{m})$ value of 3 . The resulting curve will express a distribution which is three times as heterogeneous as the random curve, and will require three times as many trees to give the same (p) value. Curves for a heterogeneity of 5 or any other value may be plotted in the same way.

The relationship between the four variables involved in a heterogeneous distribution may be expressed as follows:-

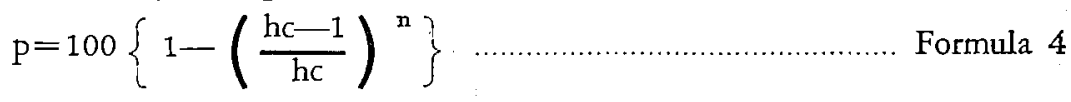

\section{ACtual Distribution}

We now have to deal with the actual data collected in the Prairie Provinces by the Dominion Forest Service. Unfortunately, the data for Manitoba is not compiled in such a manner as to be available for a study of the relationship between percentage of successful quadrats and number of trees per acre. Studies in 1947 and 1948 in northeastern and northwestern Saskatchewan, however, can be used. Both these areas are included within Section B 18, or the Mixedwood Section of the Boreal Forest Region as outlined in the Forest Classification for Canada. This Mixedwood Section includes the uplands of western Manitoba. It is likely that conditions in the Manitoba Lowlands, Section B 15, will be sufficiently similar to make the conclusions from the Mixedwood Forest of Saskatchewan applicable also to this Section.

In 1947, 1308 plots were examined in northeastern Saskatchewan, and in 1948, 2068 plots were examined in northwestern Saskatchewan. The total number of plots was therefore 3376. As each plot consisted of 20 quadrats, the total number of quadrats was 67,520 . The number of plots examined in Manitoba in 1946 was 1818 , or 36,360 quadrats.

The data for Saskatchewan has been plotted in Fig. 3, with per cent successful quadrats as the ordinate and number of trees per acre as the abscissa, the quadrat size being one milacre. As the data for the individual plots was not available to the writer, the data from the summaries for types and method of disturbance, (logging, fire, or both), was used. Regeneration of conifers was plotted first, and then regeneration of all species, including conifers, was added in order to extend the curve to the right.

An inspection of Fig. 3 will show that heterogeneity has a wide range, most of the points lying between $(\mathrm{h})$ values of 2 and 7 . In only one case was there an approach to random distribution, this including all species, while a few of the points representing softwood regeneration had (h) values as high as 10. Taking softwoods alone, the (h) values tend to increase with 
density. In a very general way the curve for $h=5$ best represents the conifers, and $\mathrm{h}=3$ all species. It may be stated then that the heterogeneity index or $(\mathrm{h})$ value for regeneration in the Mixedwood Section of the Boreal Forest is approximately 5 for softwood and 3 for softwood and hardwood combined.

\section{ApPlication}

If the (h) value for regeneration is known, we can find the average per cent quadrat stocking without conducting a survey, provided the number of trees per acre is known. For example, a cut-over area in Section B.18 is

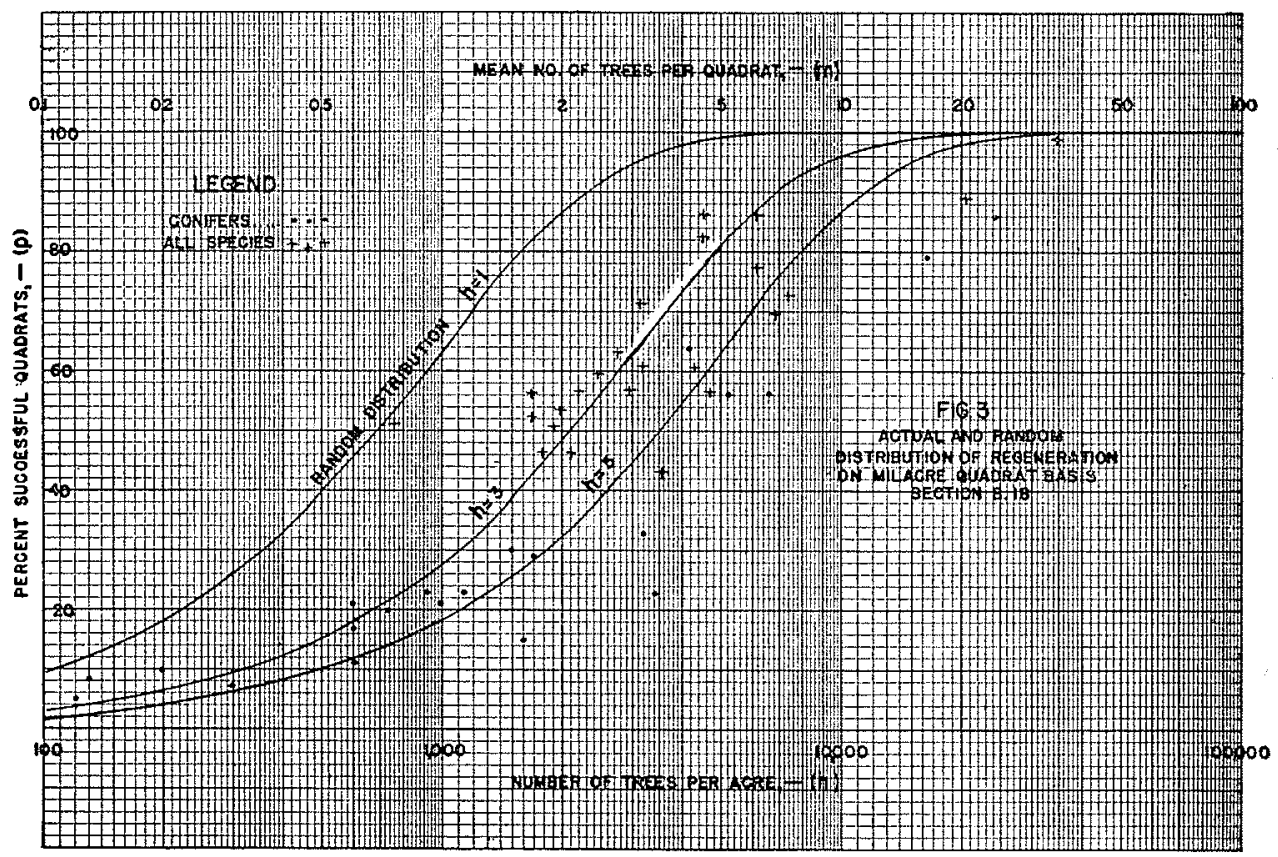

known to have 2100 seedlings per acre. If the $(h)$ value is 3 , a glance at Fig. 3 will show that the $(\mathrm{p})$ value will be 50 .

Again, we may know the per cent quadrat success but not the number of regenerated trees per acre. For example, the quadrat success in spruce regeneration in a black spruce type at Fisher Bay in the Manitoba Lowlands Section is 37 per cent according to the Regeneration Survey. The stand per acre is not given, but using Fig. 3, and assuming an (h) value of 5 , a regeneration of 2350 spruce trees per acre may be predicted.

The use of this method is of course not necessarily confined to reproduction. Mature stands may also be studied in the same way. It is thought that this method would be useful, for example, in a study of the number of spruce trees required in the white spruce-aspen type, in order to get the greatest volume in feet board measure at maturity. Some better than average 
stands have only about 50 white spruce trees per acre, 61 years and older, with a volume of around 10,000 ft. B.M. per acre. Using an (h) value of 3 , quadrat success would be around $11 / 2$ per cent for this species in this age group. If the white spruce of all ages is included, the total per acre is around 350 , indicating a quadrat success of about 11 per cent. This example indicates that the very poor success in regeneration of white spruce in the Mixedwood Section of the Prairie Provinces, as shown by the regeneration survey to date, may be more apparent than real.

It may be expected that other forest sections and regions will have their own (h) values. These values can be found with little difficulty, provided regeneration data on the basis of percentage frequency of milacre plots plus number of trees per acre is available. It is only necessary to plot the points for the different stands as explained in Section (6) above and illustrated in Fig. 3. If such data is not available, it will have to be obtained by the method explained in Section (1) above.

Since some regeneration surveys have used quadrat sizes other than one milacre, the question arises, how the data compiled on these surveys can be brought to the same terms as the milacre surveys. For example, pulpwood limits in the Lake of the Woods section have been surveyed for regeneration on the basis of 600 quadrats per acre, and show various percentage success for different areas. We wish to express the percentage success, as it would have been in a milacre quadrat survey.

If the young trees were distributed strictly at random as they would be in a homogeneous universe, the solution of the problem would be very simple, and might be expressed as follows:

Using Fig. 2 as a base, draw the curve representing $c=600$ by the method outlined in Section (4) above. Then for each ( $P$ ) value on the 600 curve, find the corresponding $(n)$, and for this $(n)$ value find the corresponding $(p)$ value on the 1,000 curve. For example, 63 per cent on the 600 curve is coupled with 600 trees per acre, and 600 trees per acre is coupled with 45 per cent on the 1,000 curve.

If the two universes have the same heterogeneity, the problem of conversion is still fairly simple. For example, if the $(h)$ value is 5 , then $p=63$ on the basis of 600 quadrats to the acre representing not 600 trees as before but 3,000 . When conversion is made to the 1,000 quadrat basis, then $p=45$ will represent not 1,000 trees but 3,000 , that is, the $(h)$ value will be 3 . It will be noted that in order to define heterogeneity, it is necessary to know both the $(h)$ and the (c) values, and that these values vary inversely as one another, or putting it in another way, ( $h c$ ) is a constant for each universe, or for all universes with the same heterogeneity.

If the two universes are different with respect to heterogeneity ( $h \mathrm{c}$ ) ceases to be constant, but it is still quite a simple matter to convert from the ( $p$ ) value of the one condition to that of the other, by the help of Fig. 2. For example, we have $p=63, h=5, c=100$, and $n=500$, and wish to find the (p) value in a universe where $h=2, c=1000$, and $(n)$ remains as before. Since $h c=500$ in the first case, and 2000 in the second, we locate the $p=63$ 
intercept on the $c=500$ curve and drop down on the $(n)$ value of 500 to intercept the $c=2000$ curve at 22 per cent.

In conclusion it might be pointed out that this paper deals mainly with the mathematical theory of distribution. The only actual field data presented, refers to regeneration in one Forest Section. It is hoped that other foresters may obtain some help from this theoretical presentation in studying regeneration in their own sections. The theory should also be tested by data obtained from distribution studies in older stands. The relationship of "normal" stocking to the various types of stocking presented here, should also be examined.

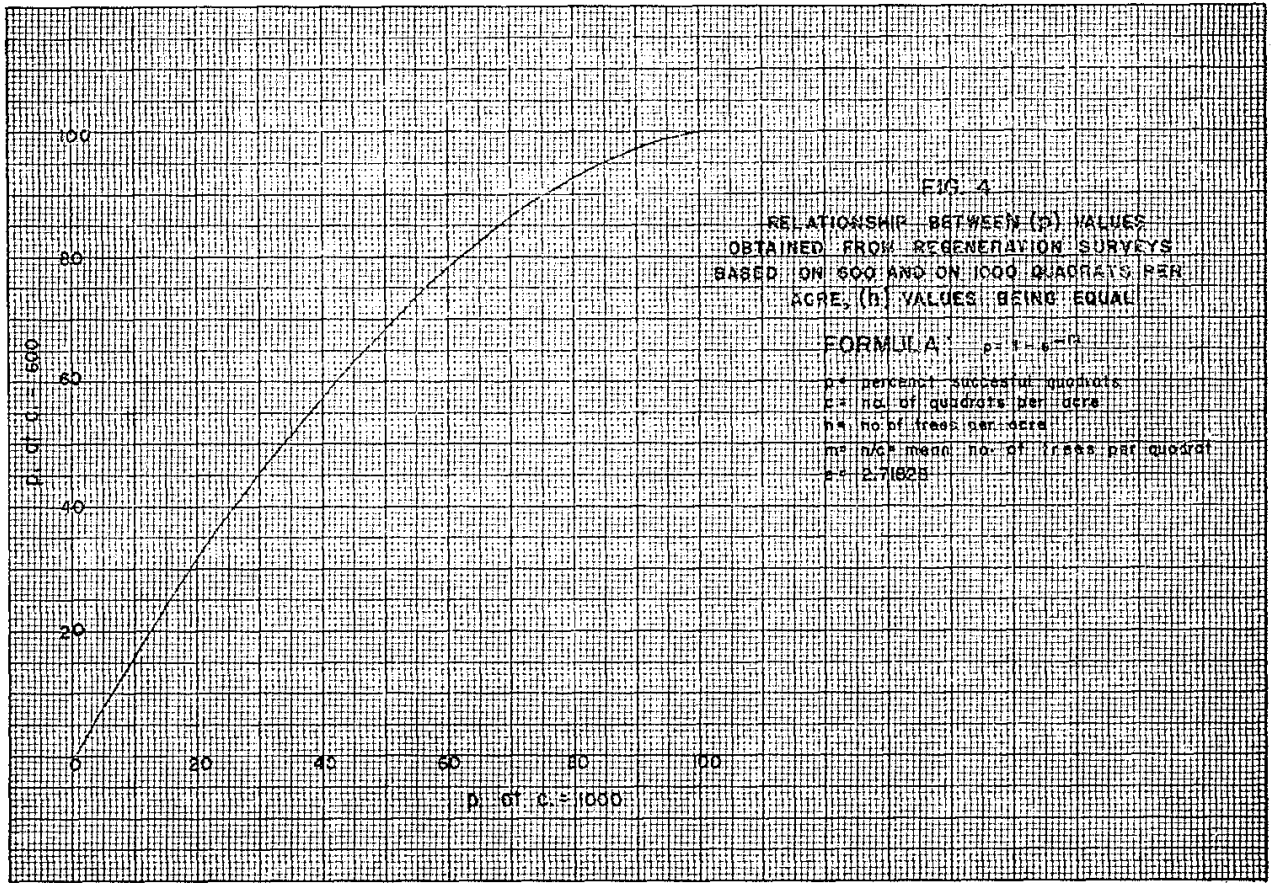

\section{SUMMARY}

Three types of distribution of trees are described. The first, called systematic, is found in plantations. The second, called random, is found where all conditions of seed-bed, seed dispersal and seedling survival are homogeneous. The third, named heterogeneous, is found where some or all of these conditions depart from homogeneity.

Formula and graphs are presented, showing the relationship of four variables, i.e., quadrat size, number of trees per acre, per cent successful quadrats, and heterogeneity of conditions.

The mathematical theory is tested against field data collected by the Dominion Forest Service in B. 18, the Mixedwood Section of the Boreal Forest. 


\section{ACKNOWLEDGMENTS}

Acknowledgment is made of assistance in the form of helpful ideas and constructive criticism, received from various foresters, of whom special mention should be made of J. L. Farrar and J. S. Rowe of the Dominion Forest Service at Ottawa and Winnipeg respectively, also Ross Grinnell of the Department of Lands and Forests, Toronto.

\section{REFERENCES}

Dominion Forest Service-Unpublished reports on Regeneration in the Mixedwood Section of the Boreal Forest, 1947 and 1948.

Larsson, H. C. and Wilkes, G.--"Forest Regeneration Survey on Cut-Over, Spruce and Pine Lands in the Thunder Bay and Western Regions," Dept. of Lands and Forests, Ontario.

Lynch, D. W. and Schumacker, F. X.-_."Concerning the Dispersion of Natural Regeneration", Journal of Forestry, January 1941.

Singh, B. N. and Das, K.--"Percentage Frequency and Quadrat Size in Analytical Studies of Weed Flora," Journal of Ecology, February 1939.

Wellner, C. A.- "Relationships between Three Measures of Stocking in Natural Reproduction of the Western White Pine Type", Journal of Forestry, August 1940. 